\title{
NuMA: A Bipartite Nuclear Location Signal and Other Functional Properties of the Tail Domain
}

\author{
Catherine Gueth-Hallonet, Klaus Weber, and Mary Osborn ${ }^{1}$
}

Department of Biochemistry, Max Planck Institute for Biophysical Chemistry, P.O. Box 2841, D-37018 Goettingen, Germany

Nuclear Mitotic Apparatus protein (NuMA) is a 238kDa protein of the nuclear matrix in interphase that relocates to the spindle poles in mitosis. The globular tail domain (residues 1701 to 2115) contains the nuclear targeting sequence, the site for binding to the mitotic spindle as well as a site responsible for nuclear reformation. To more precisely map these sites, we inserted full-length human NuMA and 16 derivatives with increasing truncations of the tail domain into the pCMV5 vector and induced transient expression. NuMA was found in the interphase nucleus of all transfected BHK cells expressing either full-length NuMA or NuMA mutant proteins ending at or after residue 2005. In contrast, mutants ending at or before residue 2003 remained in the cytoplasm. In the fulllength NuMA molecule, point mutations at position 1988 or 1989 or a double mutation at residues 2004 and 2005 cause NuMA to accumulate in the cytoplasm of both BHK and HeLa cells. The combined results indicate a bipartite nuclear location signal involving the sequences RKR (1987- 1989) and KK (2004-2005) which are separated by 14 amino acid residues. In $30 \%$ of BHK cells transfected by the full-length clone, cytoplasmic aggregates of NuMA that colocalize with the centrosomes were documented in addition to the nuclear staining. In cells with large aggregates the cytoplasmic microtubular profile was disturbed. Observation of micronuclei formation suggests that a region important for normal nuclear reformation lies in the C-terminal 130 residues. Finally, NuMA mutant proteins ending at or after residue 1800 bound to the spindle poles of mitotic cells, while NuMA proteins ending at or before residue 1750 did not. 1996 Academic Press, Inc.

\section{INTRODUCTION}

The Nucl ear Mitotic Apparatus protein (NuMA) relocates from the nucleus of interphase cells to the spindle poles of mitotic cells after nuclear envelope breakdown.

\footnotetext{
${ }^{1}$ To whom correspondence and reprint requests should be addressed at Max Planck I nstitute for Biophysical Chemistry, Am F assberg 11, D-37077 Goettingen, Germany. Fax: +49 5512011578.
}

This striking cell cycle-dependent change in cellular location was first described in immunofluorescence microscopy by Lydersen and Pettijohn [1] using a human autoantiserum and more recently by other laboratories using a variety of monoclonal antibodies and autoimmune sera that recognize the 238-kDa NuMA protein [2-6]. In mitosis, NuMA specifically associates with spindle poles and with the minus ends of mitotic microtubules (above references) while in vitro it binds to taxol-stabilized brain microtubules [4, 7]. Injection of the SPN-3 NuMA monoclonal antibody into interphase Hela cells causes a block at the next mitosis, and/or spindle aberrations $[2,8]$, while injection of a NuMA rabbit antibody into metaphase CV 1 cells induces spindle collapse [9]. These results demonstrate a role for NuMA in the dynamics of the mitotic spindle. Other evidence supports a role of NuMA in the architecture of the interphase nucleus and sequential fractionation experiments show that NuMA is a component of the nuclear matrix $[1,2,10,11]$. In addition, nuclear assembly can be perturbed by injecting the SPN-3 NuMA monoclonal antibody. For instance, injection of this antibody into PtK 2 cells during prophase induces micronuclei in $90 \%$ of the postmitotic cells [8].

Human NuMA has been doned and sequenced. Analysis of the inferred protein sequence by secondary structural prediction rules suggests a threedomain organization, i.e., a long central $\alpha$-helical domain of coiled coil forming ability flanked by gl obular head and tail domains $[6,9,12,13]$. Circular dichroism measurements of recombinant NuMA and some of its derivatives show that the central domain is $90 \% \alpha$-helical, while chemical crosslinking emphasizes the dimeric nature of the central rod domain. It reflects a double-stranded coiled coil in which the two $\alpha$-helices are arranged in parallel without a stagger [14]. Electron micrographs of full-length recombinant NuMA and of its domains have directly visualized the tripartite structure. The NuMA rod domain is with 207 $\mathrm{nm}$ the longest coiled coil currently known. Thus far recombinant NuMA from Escherichia coli has not shown assembly in vitro into filaments or other higher-order structures [14].

Recent experiments have emphasized the importance of the globular tail domain, since (1) it contains 


\section{A}

65 2710

$\lambda 1$ 2163 7145

$\lambda 2$

B

$\left.\overbrace{\text { Eco RI }}^{65} \stackrel{\text { Bst EII }}{2292}_{\text {Bsi WI }}^{4602}\right|_{\text {Eco RI }} ^{7145}$

C

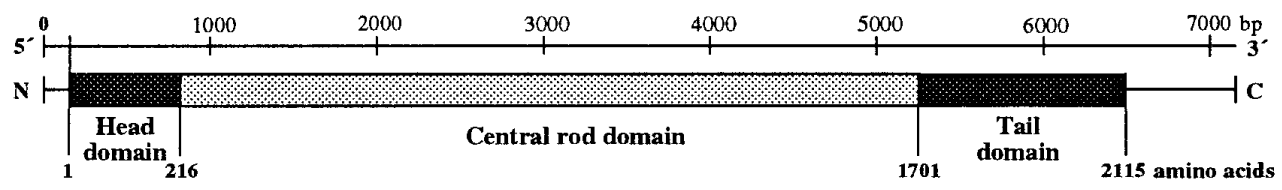

FIG. 1. NuMA CDNA clones (A), restriction map (B), and secondary structure of the NuMA protein (C) (numbering system [9]).

the nuclear targeting sequence $[10,13,15]$, (2) transfected cells expressing NuMA lacking the tail domain form micronuclei after transiting normally through mitosis [10], (3) mutant NuMA lacking this domain does not bind to the mitotic spindle, whereas a carboxy-terminal NuMA fragment (residues 1032 to 2115) does bind [13], (4) certain NuMA fragments cosediment with brain microtubules, suggesting that a sequence present in the globular tail domain may associate directly with microtubules [13], (5) many protein kinase recognition motives, and in particular four potential cdc2 kinase phosphorylation sites, are localized in the carboxy-terminal region $[9,12,16]$, and (6) alternative splicing of a common RNA transcript from the single N uMA gene generates three NuMA isoforms which differ in the lengths of their tail domains [6, 15].

These results have led us to analyze more precisely the functions associated with the tail domain. We have induced transient expression of recombinant fulllength human NuMA, as well as of 16 NuMA derivatives with increasing truncations of the tail region, in hamster BHK cells and human HeLa cells. We have been able to define and precisely map a bipartite nuclear localization signal (NLS) as well as to define a region involved in nuclear assembly and a spindle association region in the NuMA tail domain.

\section{MATERIALS AND METHODS}

Construction of full-length and recombinant NuMA cDNA. Fulllength (FL) human NuMA CDNA was constructed from the $\lambda 1$ and $\lambda 2$ overlapping CDNA fragments (Fig. 1A [14]) in the eukaryotic expression vector pCMV5 which contains the strong promoter regulatory region of the human cytomegal ovirus [17]. The $\lambda 1$ fragment was inserted in the unique EcoRI cloning site of the pCMV5 vector. The $\lambda 2$ fragment was cloned into the EcoRI site of the pBs.SK vector
(Stratagene, Heidelberg, FRG) and then isolated using the NuMA BstEII and the vector Kpnl restriction sites (Fig. 1B). Subsequently, $\lambda 2$ was ligated into the BstE II/Kpnl-linearized pCMV5 vector containing the $\lambda 1$ fragment, thus yielding FLNUMA CDNA in pCMV5. The FL human NuMA construct contained NuMA nucleotides 65 to 7145 and included the NuMA start codon (nucleotides 157-159).

A nested series of mutant NuMA CDNAs progressively truncated in the $3^{\prime}$ end was constructed. This was done by ligating the $5^{\prime}$ portion of FLNUMA in PCMV5, obtained after Bsi WI (Fig. 1B) and BamHI (vector cloning site) digestions, with different DNA fragments obtained by PCR amplification and Bsi WI and BamHI treatment after cloning in the PCR II vector (I nvitrogen). PCR amplification was performed with Vent polymerase (New England Biolabs, Schwalbach, FRG), which ensured high-fidelity base incorporation due to its $3^{\prime}$ to $5^{\prime}$ proofreading exonuclease activity. The FLNuMA in pCMV 5 was used as template. The forward primer sequence was common to all truncated mutants. It corresponded to the NuMA cDNA complementary sequence between nucleotide positions 4602 and 4630 and thus included the Bsi WI site. The reverse primer was specific for each mutant. The sequence from the $5^{\prime}$ to $3^{\prime}$ ends consisted of the GGCAT sequence flanked by the EcoRI restriction site, then the TTA stop codon, and finally the appropriate NuMA cDNA antisense sequence of 26 nucleotides, e.g., nucleotide positions 4833 to 4807 were used to generate the $\Delta 1559$ recombinant NuMA clone. The number following the $\Delta$ symbol shows the carboxy-terminal amino acid of each of the 16 NuMA mutants constructed in this study. For construction of site-directed mutagenesis recombinants, the mutation was also generated using the PCR technique on the $\lambda 2$ fragment subcloned into the $\mathrm{BamHI}$ and $\mathrm{Kpnl}$ sites in the $\mathrm{pUC18}$ vector (New England Biolabs), since this vector lacks BstXI sites. For the NuMA CDNA sequence mutated in amino acid residues 2004 and 2005 (NuMA FL m2004 + 2005), a specific forward primer coding for the NuMA sequence 6136 to 6177 and thus containing the BstXI site was used. This primer contained $\mathrm{A} \rightarrow \mathrm{T}$ changes at positions 6167 and 6170 . The reverse primer was coding for a stop codon immediately followed by the 6503 to 6478 NuMA antisense sequence. The PCR-amplified fragment subcloned in the PCRII vector was released by BstXI and Kpnl digestion and ligated in the $\mathrm{pUc18}$ vector containing the NuMA $\lambda 2$ fragment digested by the same enzymes. For the FLNUMA CDNA sequence mutated at residue 1984, 1988, or at residue 1989 (FLm1984, FLm1988, and FLm1989), the forward primer was the same as for the truncated mutants. The reverse 
primer for FL m1984 consisted of the NuMA antisense sequence 6153 to 6099 in which the $C$ in position 6106 was replaced by a G. For FLm1988 and FLm1989 the antisense sequence 6153 to 6111 (containing the BstXI restriction site) was used. For FLm1988 the A in position 6119 was replaced by a $T$ and for $F L m 1989$ the $C$ in position 6121 was replaced by a G. PCR fragments amplified in the pCRII vector were released by BstXI and Bsi WI digestion and ligation in the pUc18 vector containing the NuMA $\lambda 2$ fragment digested by the same enzymes. FL mutant NuMA constructs were obtained by ligation of the fragment released by BstEII and Kpnl digestion into the pCMV5 vector containing the wild-type NuMA CDNA sequence digested by the same enzymes. For each missense mutant the sequence was checked by DNA sequencing and no mutation other than that introduced by the site-directed mutagenesis was found in the more than 400 nucleotides analyzed.

Transfection. Cells were grown in DME plus 10\% fetal calf serum. For transfection experiments, BHK cells were grown for $24 \mathrm{~h}$ on glass coverslips coated with polylysine $(10 \mu \mathrm{g} / \mathrm{ml})$. At the time of transfection $(\mathrm{t}=0)$, cells were $50 \%$ confluent. They were transiently transfected using the modified calcium phosphate precipitation technique [18]. Briefly, $14 \mu \mathrm{g}$ of plasmid DNA was washed with ethanol, lyophilized, and dissolved in $300 \mu \mathrm{l}$ of a $250 \mathrm{mM}$ calcium chloride solution followed by the addition of $300 \mu \mathrm{l}$ of $50 \mathrm{mM}$ BES-buffered saline (50 mM BES, $280 \mathrm{mM} \mathrm{NaCl}, 1.5 \mathrm{mM} \mathrm{Na}_{2} \mathrm{HPO}_{4}, \mathrm{pH}$ 6.96). After $10 \mathrm{~min}$ at room temperature, this solution was added dropwise to cells on coverslips in a $60-\mathrm{mm}$ diameter petri dish containing 3 $\mathrm{ml}$ of medium. After 12 to $24 \mathrm{~h}$ at $35^{\circ} \mathrm{C}$, with $3 \% \mathrm{CO}_{2}$, cells were washed with PBS, $5 \mathrm{ml}$ of fresh medium was added, and the cells returned to $37^{\circ} \mathrm{C}$ with $5 \% \mathrm{CO}_{2}$.

Primary antibodies and immunofluorescence microscopy. NuMA SPN-3 monoclonal antibody was used as undiluted hybridoma supernatant [2]. It recognizes human but not hamster NuMA. The $\gamma$ tubulin antibody was an anti-peptide rabbit serum (serum 75 [19]) used at a dilution of 1:1000. Human autoantiserum 5051 was used as a centrosome marker [20] at a 1:30 dilution. Microtubules were visualized with an affinity-purified rabbit tubulin antibody [7]. Immunofluorescence was by standard procedures on cells fixed in methanol for $6 \mathrm{~min}$.

Gel electrophoresis and immunoblotting. Polypeptides were separated on $7.5 \%$ SDS - polyacrylamide gels and transferred el ectrophoretically to nitrocellulose. I mmunostaining with the SPN-3 antibody and peroxidase-labeled anti-mouse antibodies (Dako, Hamburg) diluted 1:5000 used the ECL technique (cf. [2]).

\section{RESULTS}

\section{Expression of Recombinant Full-Length NuMA Protein in Hela and BHK Cells}

FL human NuMA cDNA was cloned and inserted in the eukaryotic expression vector pCMV5. Transcription of this CDNA was under the control of the powerful promoter regulatory region of the human cytomegal ovirus major immediate early gene. The expression of recombinant human NuMA protein was monitored using the SPN-3 monodonal antibody, which recognizes endogenous NuMA in human HeLa cells but not in hamster BHK cells [2].

Figure 2 shows SPN-3 immunoblots of HeLa and $\mathrm{BHK}$ whole cell extracts harvested $48 \mathrm{~h}$ after transfection with $\mathrm{FL}$ human NuMA CDNA. A single band at $\sim 240 \mathrm{kDa}$ was detected in both control and transfected HeLa cells (Fig. 2A). However, when the same number of cells was applied to each lane of the gel, the intensity of the band was twofold higher for the transfected than for the control HeLa cells (compare lanes 1 and 2 in Fig. 2A). Immunofluorescence of parallel cultures on coverslips showed that $5 \%$ of the cells were transfected. These showed a much more intense staining than the untransfected control cells (cf. Fig. 3A). Thus, on a per cell basis, transfected HeLa cells express around 40 times more NuMA protein than do control cells. In immunoblots of BHK cells transfected with FL human NuMA cDNA, the SPN-3 antibody detected human NuMA protein with the correct molecular weight of $\sim 240 \mathrm{kDa}$, while no protein reacting with SPN-3 antibody was detected in mock-transfected BHK cells (Fig. $2 B$, lanes $6^{\prime}$ and $1^{\prime}$ ). I mmunofluorescence of parallel cultures on coverslips showed that $15 \%$ of the cells were transfected.

Immunofluorescence staining with SPN-3 antibody showed a larger amount of NuMA in transfected than in nontransfected HeLa cells as soon as $12 \mathrm{~h}$ posttransfection (Figs. $3 A$ and $3 A^{\prime}$ ). In contrast, when the same construct was introduced in BHK cells, only transfected cells were stained with SPN-3 antibody (Figs. 3B and 3B'). In both cases, transfected FL human NuMA localized to the nucleus but not the nucleolus in interphase cells and to the spindle poles in mitotic cells (Fig. 3). Some $5 \%$ of transfected HeLa cells and $30 \%$ of transfected BHK cells displayed in addition to staining of nuclei a single cytoplasmic aggregate (Figs. 4A-4B" and 5A-5A" for BHK cells). In cells stained $12 \mathrm{~h}$ posttransfection the cytoplasmic aggregates were small and usually located close to the nuclear periphery. In cells stained 24 or $48 \mathrm{~h}$ posttransfection, the aggregates ranged from dot-like structures to massive accumulations which occupied a large part of the cytoplasm. Double-label experiments showed a correlation between the position of the aggregate monitored with SPN-3 antibody and of the centrosome visualized with the 5051 antiserum or $\gamma$-tubulin antibodies. The cytoplasmic NuMA aggregate either surrounded the centrosome or abutted onto it (Figs. 4A-4A" and $\left.4 B-4 B^{\prime \prime}\right)$. In a few cells, filament bundles staining for NuMA were seen in the cytoplasm (Fig. 4D).

The colocation of the centrosome, which represents the major microtubule nucleating center of the interphase cell, and the cytoplasmic NuMA aggregate led us to analyze the distribution of the microtubular network in transfected cells. The microtubular network of cells which lacked cytoplasmic aggregates and in which transfected NuMA was present only in the nucleus was indistinguishable from that of control nontransfected BHK cells. Double immunofluorescence microscopy with SPN-3 and tubulin antibodies showed that the microtubule network was often modified in the $30 \%$ of transfected BHK cells displaying cytoplasmic NuMA aggregates. In such cells tubulin staining was concen- 
A

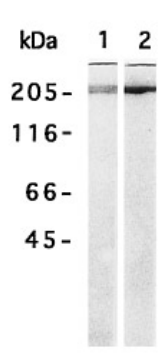

B

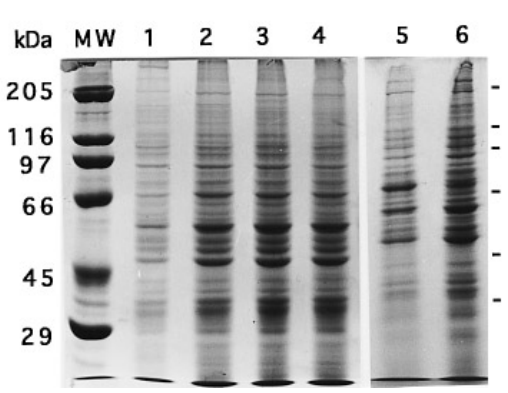

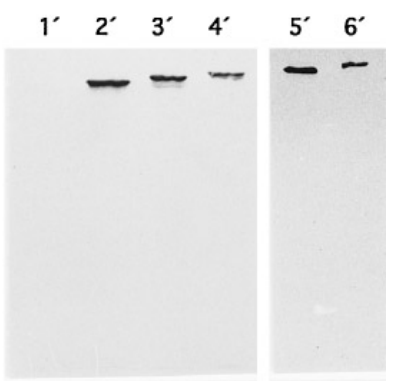

FIG. 2. Expression of $F L$ and truncated human NuMA proteins assayed by SDS gel electrophoresis and immunoblotting $48 \mathrm{~h}$ after transfection. (A) Immunoblot detection of FL human NuMA in human HeLa cells. The NuMA monoclonal antibody detected both the endogenous and recombinant human proteins. Lane 1, mock transfected; lane 2, the same number of cells transfected with FL human NuMA CDNA. (B) Expression of FL and truncated human NuMA proteins in hamster BHK cells. Lanes 1-6, Coomassie blue staining of whole cell extracts after transient transfection with different recombinant CDNAs. Lanes $1^{\prime}-6^{\prime}$, I mmunoblot detection of recombinant NuMA proteins with SPN-3 antibody. Lanes $1,1^{\prime}$, mock transfected; lanes 2, 2', recombinant $\Delta 1559 ;$ Ianes 3, 3', $\Delta 1700 ;$ Ianes $4,4^{\prime}, \Delta 1800 ;$ Ianes $5,5^{\prime}, \Delta 1977$; lanes $6,6^{\prime}$, FLNuMA. Molecular weight standards are on the left (A, B: lanes 1-4, $\left.1^{\prime}-4^{\prime}\right)$ and on the right in B (lanes 5, 6 and $5^{\prime}, 6^{\prime}$ ).

trated together with the NuMA aggregate; although a microtubular network was present throughout the cytoplasm, it was less dense than that of the nontransfected cells (Figs. 5A-5A"). The degree of distortion of the microtubular network seemed to depend on the size of the NuMA aggregate, being most pronounced in cells with large NuMA aggregates.
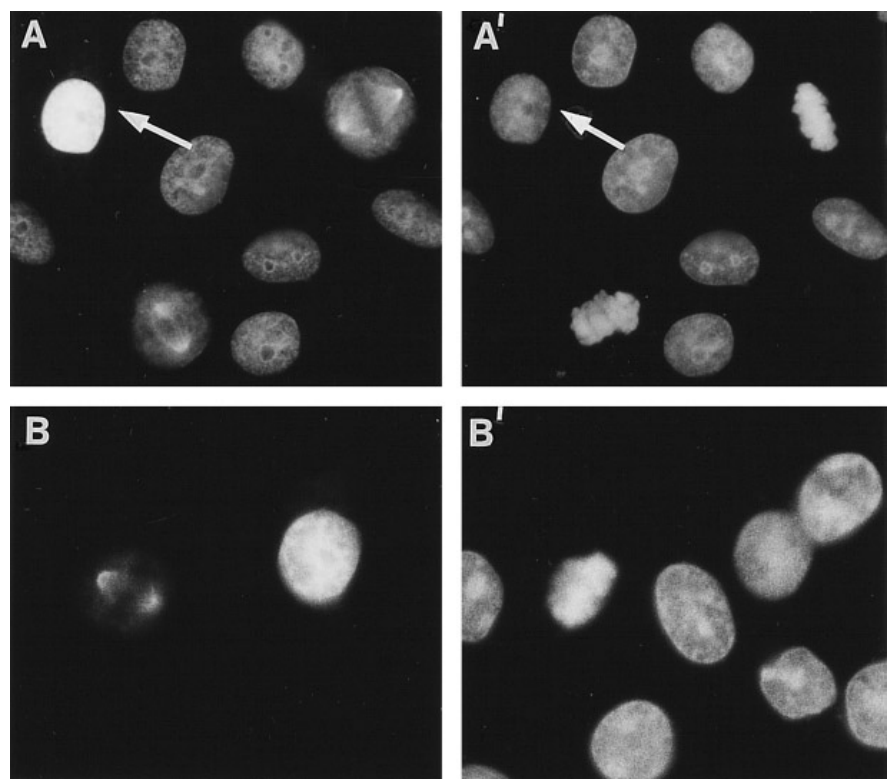

FIG. 3. Immunofluorescence with NuMA SPN-3 antibody $36 \mathrm{~h}$ after transfection with recombinant human FLNuMA. (A, $\left.A^{\prime}\right)$ HeLa stained with NuMA antibody $(A)$ and Hoechst $\left(A^{\prime}\right)$. Since the antibody detects both endogenous and recombinant human NuMA, all cells are stained. Transfected cells (arrow in A) are distinguished because they express very high levels of NuMA. (B, B') BHK cells stained with NuMA antibody $(B)$ and Hoechst $\left(B^{\prime}\right)$. NuMA is detected only in transfected cells since the SPN-3 antibody does not recognize endogenous hamster NuMA $\left(A, A^{\prime}\right) \times 600$; $\left(B, B^{\prime}\right) \times 720$.

\section{Expression of the Truncated NuMA Constructs in BHK Cells}

To analyze the functional organization of the tail domain, we originally constructed 14 NuMA mutants, truncated at different points in the C-terminal domain by an in frame stop codon. Expression was analyzed by insertion in the pCMV5 vector and transient transfection of BHK cells so as to detect the mutant human NuMA proteins after immunostaining with SPN-3 antibody without the background due to endogenous hamster NuMA protein. The SPN-3 epitope lies between residues 255 and 267 [14] and thus should detect all truncated recombinant NuMA proteins constructed in this study. Immunoblots of whole cell extracts of BHK cells transfected with different truncated NuMA cDNAs (Fig. 2B, lanes $2^{\prime}-5^{\prime}$ ) showed that all truncated NuMA proteins were expressed. The molecular weight varied according to the construct used for transfection with good agreement between the observed size ( Fig. 2B, lanes $2^{\prime}-6^{\prime}$ ) and that predicted from the size of the clones (e.g., the $\Delta 1700$ fragment: observed molecular weight $\sim 200 \mathrm{kDa}$, calculated molecular weight $193 \mathrm{kDa}$ ).

Immunofluorescence staining with SPN-3 antibody $36 \mathrm{~h}$ posttransfection allowed the NuMA constructs to be grouped in different categories (Fig. 6). When the $\triangle 2030$ construct was used, NuMA localized to the nucleus (Fig. 6A). In contrast, in BHK cells transfected with the shorter constructs, i.e., $\Delta 2003$ to $\Delta 1559$, NuMA was restricted to the cytoplasm (Figs. 6B-6E). In cells transfected with the constructs $\Delta 2003, \Delta 1977$, $\Delta 1964, \Delta 1950, \Delta 1935$, or $\Delta 1890$, NuMA staining was present in $\sim 90 \%$ of the cells in a single large cytoplasmic aggregate located close to the nucleus (Figs. 6B and 6C) which colocalized with the centrosome (Figs. 4C-4C"). In cells expressing $\Delta 2003$ or $\Delta 1977$ mutant NuMA protein, the aggregate around the 

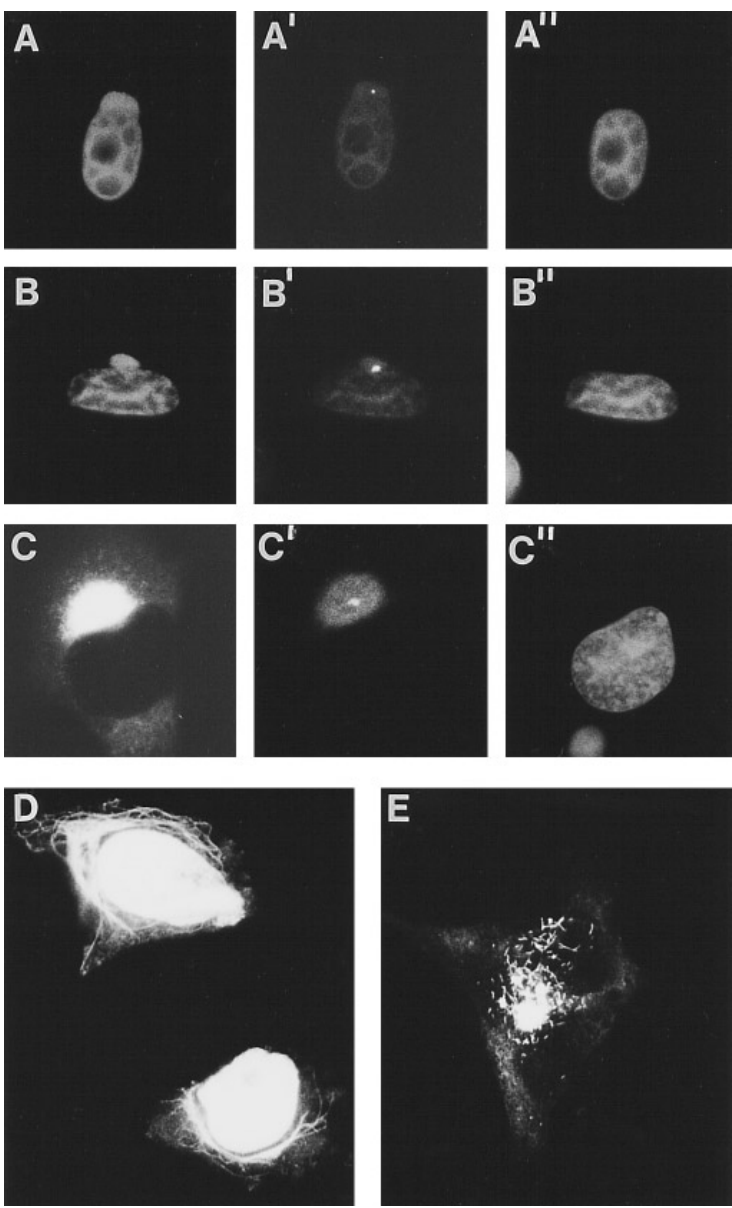

FIG. 4. I Immunofluorescence of $B H K$ cells $36 \mathrm{~h}$ after transfection with FL (A-A", B-B", and D) or truncated NuMA cDNAs [ $\Delta 1977$ cDNA (C-C" $)$ or $\triangle 2003$ CDNA (E)]. Cells were triply stained with either NuMA antibody $(A), \gamma$-tubulin antibody $\left(A^{\prime}\right)$, and Hoechst $\left(A^{\prime \prime}\right)$ or with NuMA antibody $(B, C)$, the 5051 centrosomal antibody ( $B^{\prime}$, $\left.C^{\prime}\right)$, and Hoechst $\left(B^{\prime \prime}, C^{\prime \prime}\right)$. Cytoplasmic NuMA aggregates seen in $30 \%$ of cells transfected with FLNuMA CDNA in (A) and (B), or with NuMA $\Delta 1977$ in (C), colocate with the centrosomes. (D and E) Cells stained only with NuMA antibody. Note the "filamentous" NuMA in the cytoplasm (D) and the NuMA rods in (E). $\left(A-A^{\prime \prime}\right) \times 900$; $\left(B-B^{\prime \prime}\right)$ $\times 700$; $\left(C-C^{\prime \prime}\right) \times 500$; (D) $\times 600$; (E) $\times 1000$.

centrosome appeared to be composed of distinct, short rod-like elements (Figs. 4E and 6B). In contrast, in cells expressing $\Delta 1964, \Delta 1950, \Delta 1935$, and $\Delta 1890$ mutant N UMA proteins, no substructure was visible within the NuMA aggregate. In cells transfected with shorter constructs, i.e., $\Delta 1839, \Delta 1800, \Delta 1700, \Delta 1750$, and $\Delta 1559$, NuMA was again located only in the cytoplasm, but cells either displayed multiple aggregates of varying sizes in the cytoplasm, often in proximity to the plasma membrane (Fig. 6D), or showed uniform cytoplasmic staining (Fig. 6E). No substructure was visible at the light microscopical level in the aggregates formed by these shorter mutants.

To put the data on a more quantitative basis, cells transfected by different cDNAs were examined 12 and $36 \mathrm{~h}$ posttransfection and assigned to one of three categories, i.e., homogeneous cytoplasmic staining, multiple cytoplasmic aggregates, or a single cytoplasmic aggregate. The data in Fig. 7 show that the staining patterns are construct dependent.

Examination of the microtubular network in BHK cells transfected with the truncated NuMA cDNAs showed that the overexpression of NuMA $\Delta 1950$, or of longer NuMA constructs, led to disruption of the microtubular network. (cf. Fig. 5A-5A"). In contrast, the microtubular network appeared normal in cells transfected with the mutants $\Delta 1559$ to $\Delta 1935$ even though large single or multiple cytoplasmic NuMA aggregates were present. In such cells tubulin staining was not concentrated at NuMA aggregates (cf. Figs. $5 B-5 B^{\prime \prime}$ for the $\Delta 1839$ construct).

\section{I dentification of the NuMA Bipartite Nuclear Localization Signal}

Our initial transfection experiments with BHK cells showed that NuMA $\Delta 2030$ was correctly targeted to the nucleus (Fig. 6A), whereas $\Delta 2003$ and shorter pro-
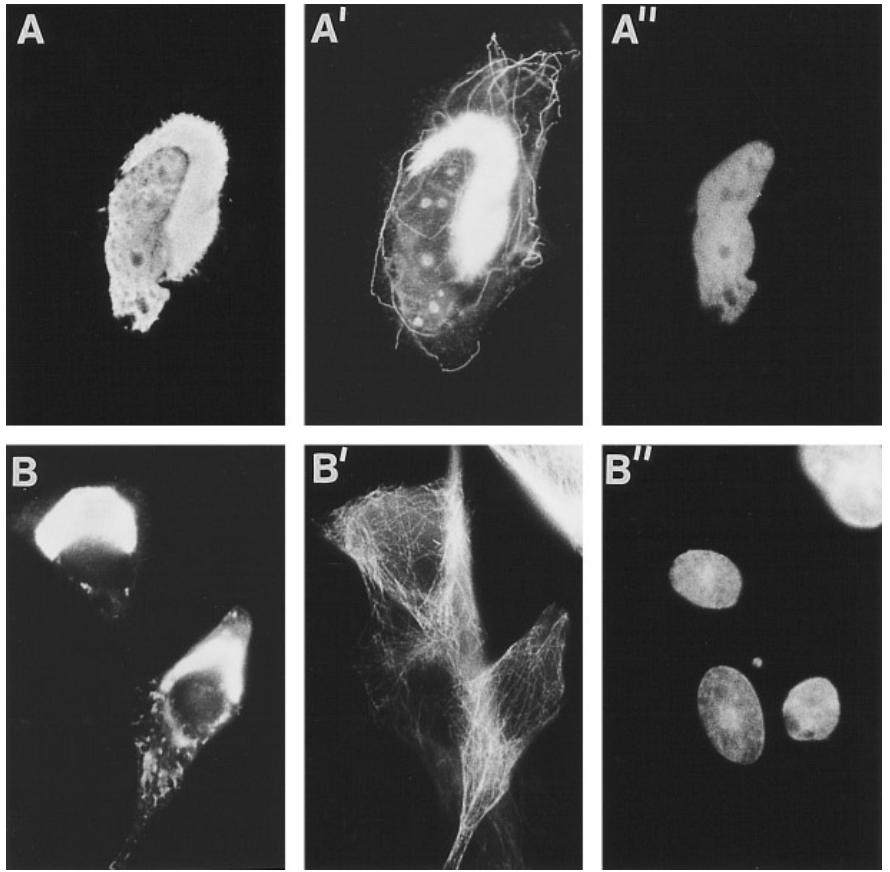

FIG. 5. NuMA and microtubular profiles in BHK cells $36 \mathrm{~h}$ after transfection with $F L$ or truncated NuMA CDNAs. BHK cells transfected with FLCDNA (A- $\left.A^{\prime \prime}\right)$ or $\triangle 1839$ CDNA (B - B" $)$. Cells were triply stained with NuMA antibody $(A, B)$, tubulin antibodies $\left(A^{\prime}\right.$, $\left.B^{\prime}\right)$, and with Hoechst dye $\left(A^{\prime \prime}, B^{\prime \prime}\right)$. NuMA and tubulin colocalize in the aggregate in $\left(A, A^{\prime}\right)$ and the number of microtubules visible in the rest of the cytoplasm in $\left(A^{\prime}\right)$ is reduced. In $\left(B^{\prime}\right)$ the NuMA aggregates are not stained by the tubulin antibody, and the microtubular profile is normal. $\left(A-A^{\prime \prime}\right) \times 300$; $\left(B-B^{\prime \prime}\right) \times 500$. 

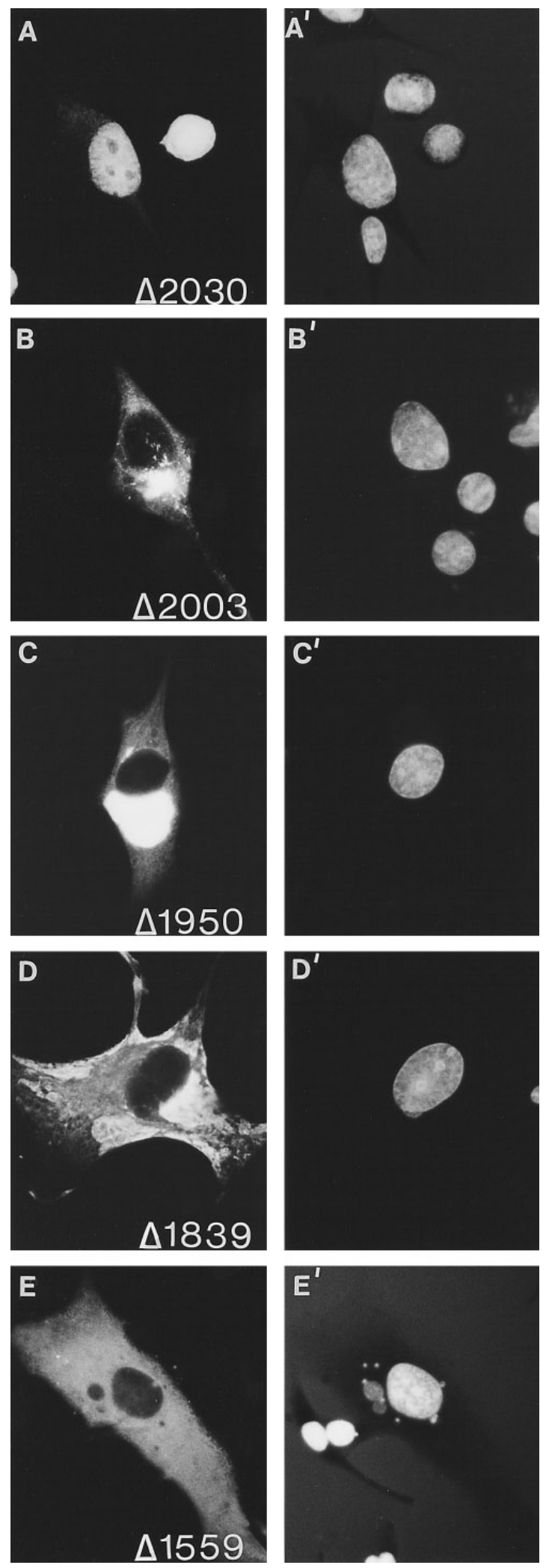

FIG. 6. I mmunofluorescence of $B H K$ cells $36 \mathrm{~h}$ after transfection by $F L$ or truncated NuMA CDNAs. $\triangle 2030$ CDNA (A, $\left.A^{\prime}\right), \triangle 2003$ CDNA $\left(\mathrm{B}, \mathrm{B}^{\prime}\right), \Delta 1950 \mathrm{CDNA}\left(\mathrm{C}, \mathrm{C}^{\prime}\right), \Delta 1839 \mathrm{CDNA}\left(\mathrm{D}, \mathrm{D}^{\prime}\right)$, and $\triangle 1559 \mathrm{CDNA}$ teins were detected exclusively in the cytoplasm (Fig. 6). Therefore, a sequence essential for nuclear targeting must be present between amino acid residues 2030 and 2003. Tang et al. [15] have shown that Lys 1988 is essential for nuclear targeting of NuMA, but the chimeric protein NuMA 1985-1991, fused to $\beta$ galactosidase which contains four basic residues ( $R$ and K) within positions 1984 to 1989, located predominantly to the cytoplasm. Prominent nuclear staining was seen only with a chimeric protein containing the longer NuMA sequence 1972-2007. These results suggested to us that the basic residues between positions 1987 and 1989 were not sufficient for nuclear targeting and that one or more amino acids between residues 2003 and 2007 were also required.

We reasoned that the two lysine residues in positions 2004 and 2005 (Fig. 8A) might be part of the nuclear location signal, since a class of bipartite nuclear targeting sequences has been described with a consensus motif which involves two clusters of basic residues [21]. To test this possibility, we first made two additional truncated constructs $\Delta 2005$ and $\Delta 2007$. Both NuMA proteins located to the nucleus of both HeLa and BHK cells (Fig. 8, Table 1).

To further define the NuMA NLS four additional fulllength point mutants were constructed with changes at the following positions: 1984, 1988, 1989, and 2004 +2005 (Fig. 8A). At 20 and 40 h posttransfection BHK and $\mathrm{HeL}$ a cells were fixed and cells assigned to one of three categories given in Table 1 . In this manner targeting to the nucleus could be evaluated and compared to that seen with either the wild-type FLCDNA or with the truncated $\Delta 2003$ and $\Delta 2005$ mutants (Fig. 8, Table 1). The point mutant F L m1984 shows an identical distribution to wild-type, i.e., the change at this position does not affect nuclear targeting. In contrast, the point mutant FLm1988 locates exclusively to the cytoplasm (Fig. 8B). In the point mutants FLm1989 and FLm2004 + 2005 NuMA is predominantly cytoplasmic by $20 \mathrm{~h}$ but by $40 \mathrm{~h}$ the majority of nuclei of both BHK and HeLa cells are weakly stained (Table 1). Thus, in these two mutants the efficiency of transport seems to be impaired in contrast to wild-type.

\section{Effects of Truncated NuMA Proteins on Nuclear Reassembly}

Postmitotic formation of micronuclei has been reported after microinjection of NuMA SPN-3 antibody

$\left(E, E^{\prime}\right)$. Cells were stained with the NuMA antibody $(A-E)$ and Hoechst $\left(A^{\prime}-E^{\prime}\right)$. Only the $\Delta 2030$ mutant is found in the nucleus, showing that residues important for the nuclear location lie between residues 2030 and 2003 . Note the different cytoplasmic patterns in (B-E). $\times 350$ except $\left(C, C^{\prime}\right) \times 450$. 
A
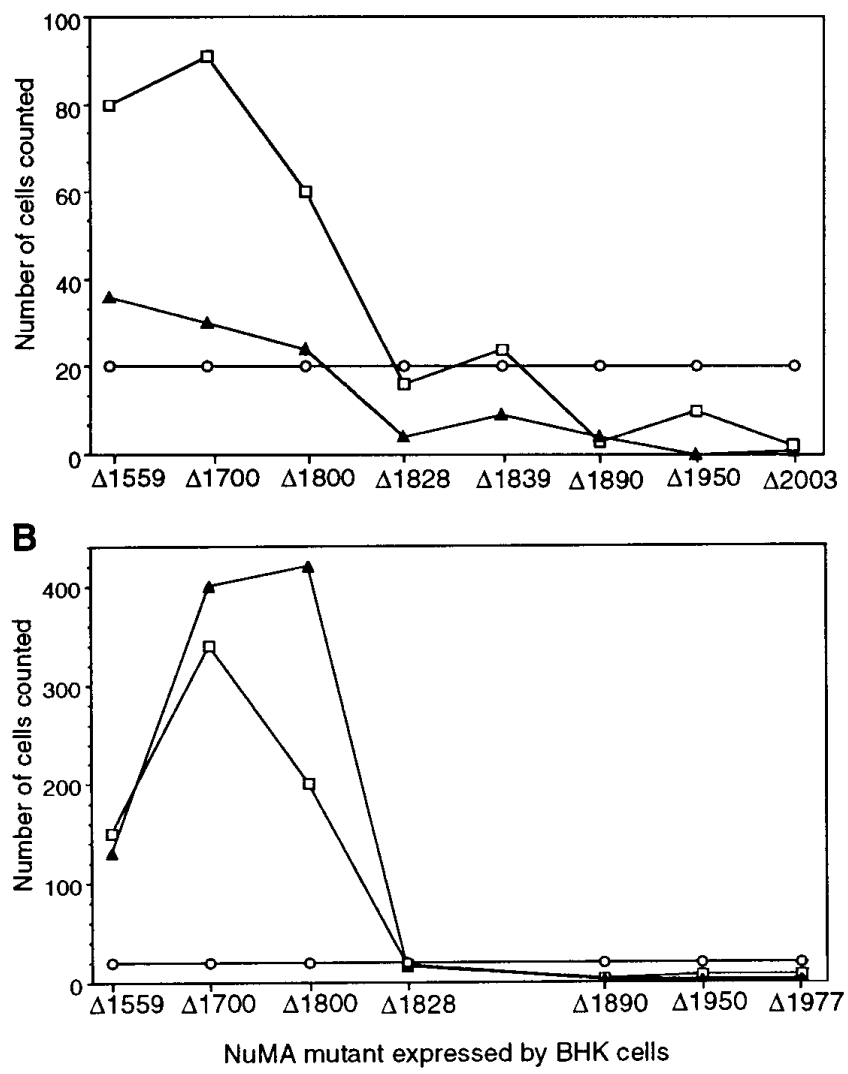

FIG. 7. Relative frequencies of different cytoplasmic NuMA staining patterns in BHK cells transfected with truncated NuMA cDNAs shown on the horizontal axis. Cells were stained with NuMA antibody and assigned to one of three categories depending on their staining pattern. ( $\square$ ) Homogeneous cytoplasmic staining; ( $\boldsymbol{\Delta}$ ) multiple cytoplasmic aggregates; $(\bigcirc)$ single cytoplasmic aggregate. For each construct sufficient cells were counted so as to include 20 cells with a single cytoplasmic aggregate. (A) $12 \mathrm{~h}$ posttransfection; (B) $36 \mathrm{~h}$ posttransfection.

[2]. It has also been observed after transfection of NuMA cDNAs carrying deletions in either the head or the tail domains [10]. We looked at the formation of micronuclei in BHK cells transfected with the FLN UMA CDNA and with five different mutant NuMA cDNAs (Fig. 9 for $\Delta 1977$ and $\Delta 1800$, Table 2). In cells transfected with the FLNuMA construct, only $1 \%$ of cells formed micronuclei $36 \mathrm{~h}$ posttransfection, while $6 \%$ of cells had micronuclei $60 \mathrm{~h}$ posttransfection. Transfection with $\Delta 2005$ resulted in $4 \%$ of cells with micronuclei $36 \mathrm{~h}$ after transfection and $13 \% 60 \mathrm{~h}$ posttransfection. In contrast, in cells transfected with the NuMA mutants $\Delta 1977, \Delta 1800, \Delta 1700$, and $\Delta 1559$ a much higher rate of micronuclei formation was seen. At $36 \mathrm{~h}$ posttransfection, $16 \%$ of cells transfected by these mutants showed micronuclei, and $60 \mathrm{~h}$ postinfection $33-46 \%$ of the transfected cells contained micronuclei (Table 2 ). In cells transfected with the $\Delta 1977$,
$\Delta 1800, \Delta 1700$, and $\Delta 1559$ constructs micronuclei did not stain for human NuMA (cf. Fig. 9), as expected from the data on nuclear localization described above.

\section{Localization of Truncated NuMA Proteins in \\ Transfected Mitotic Cells}

Mitotic spindle association of mutant NuMA proteins was analyzed by performing double-labeling experiments with SPN-3 antibody and either tubulin antibody to stain spindle microtubules or $\gamma$-tubulin antibodies to detect the spindle poles. In cells transfected with $\Delta 1800$ or longer constructs the NuMA proteins localized to the spindle poles (Figs. 10A-10A" and 10B-10B"). In contrast, in mitotic BHK cells transfected with the shorter $\Delta 1700$ and $\Delta 1559$ constructs, spindle pole association was not observed. I nstead, the SPN-3 antibody showed intense homogeneous staining throughout the cell (Figs. 10C-10C"). Quantitative data for the FLNuMA molecule and the mutants $\Delta 1839, \Delta 1800, \Delta 1750, \Delta 1700$, and $\Delta 1559$ are shown in Table 3. Spindle pole staining was present in 14/16 mitotic cells transfected with the FL molecule, 12/14 mitotic cells transfected with $\Delta 1869$, and $20 / 32$ mitotic cells transfected with $\Delta 1800$ mutant. No spindle pole staining was seen in the mitotic cells transfected with the $\Delta 1750, \Delta 1700$, and $\Delta 1559$ mutants. The results suggest that the NuMA sequence between amino acid residues 1750 and 1800 contains information necessary for spindle pole localization.

The staining at the spindle poles did not always appear normal in the transfected cells. I ndeed, large round aggregates were more frequent than the dot- or crescent-like appearance typically seen when endogenous NuMA is assayed (Fig. 10 and Table 3). However, polar aggregates also predominate in mitotic cells transfected with the FLNuMA. Thus, such staining patterns may be due to the presence of excess NuMA molecules dueto over expression rather than to a difference in binding characteristics resulting from the truncation at the carboxy-terminal end.

The results on nuclear localization, cytoplasmic aggregates, filament-like staining, and effects on the microtubule pattern are summarized for FLNuMA and for each of the constructs in Table 4.

\section{DISCUSSION}

\section{NuMA Nuclear Localization Signal}

Defining the NLS in NuMA has not proved easy. Compton et al. [10] stated that "the primary sequence of NUMA does not reveal a putative NLS similar to that defined for $\mathrm{T}$ antigen or the variation of this NLS found in nucleoplasmin." In contrast, Yang et al. [9] drew attention to a potential NLS between residues 217- 221 (RRLKK). However, Maekawa and Kuriyama 

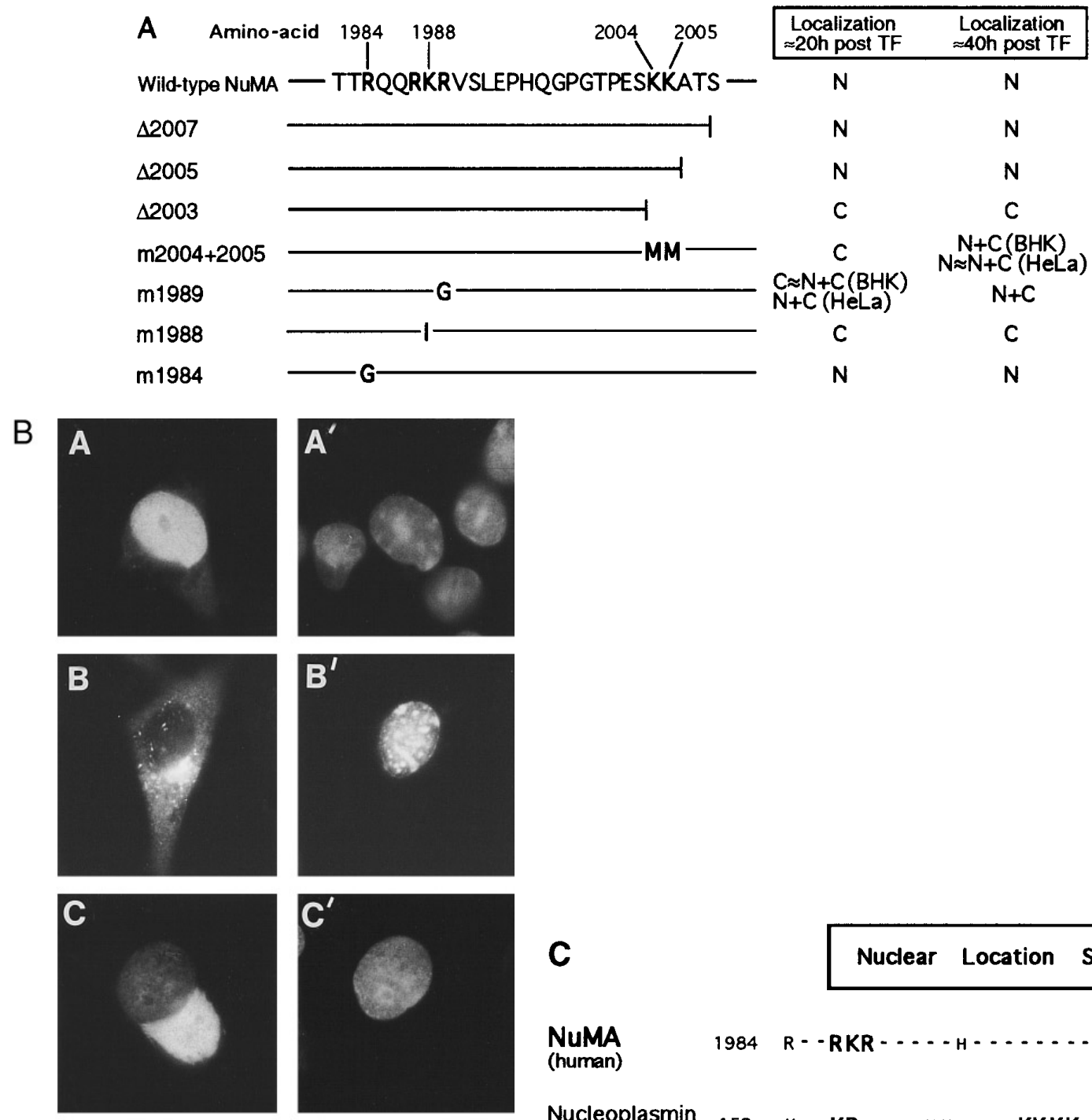

\section{C}

\section{Nuclear Location Signal}

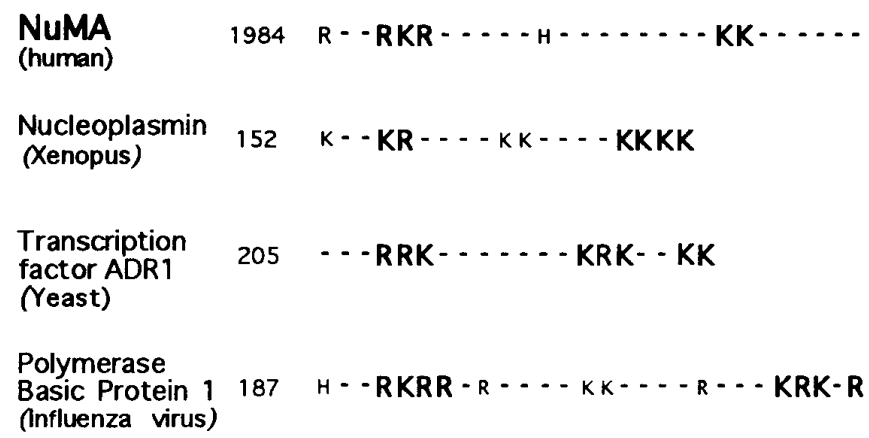

FIG. 8. Determination of the NuMA nuclear location signal. (A) Interphase localization of expressed wild-type NuMA and truncated $(\triangle)$ or point mutants $(\mathrm{m})$ in transfected BHK and HeLa cells. N, nuclear staining only; N + C, nuclear + cytoplasmic stain; C, cytoplasmic stain alone. Only the most frequent phenotype(s) encountered for each construct has been noted here (see Table 1). In the case of different results for BHK and HeLa cells, both are given. (B) Immunofluorescence of BHK cells $36 \mathrm{~h}$ after transfection with different truncated or missense NuMA cDNAs. (A, A') $\Delta 2005$, (B, B') $\Delta$ 2003, (C, C') FLm2004 + 2005, (D, D') FLm1988. Cells were stained with NuMA antibody $(A-D)$ and Hoechst $\left(A^{\prime}-D^{\prime}\right) \times 500$. (C) Comparison of the NuMA NLS motif with bipartite motifs for other nuclear proteins (for references see text). Basic amino acids are represented by their single-letter code; other residues by a dash. Basic residues in the bipartite motif are in heavy type, others are in smaller type.

[13] showed subsequently that an amino-terminal fragment (residues 1-1028) was located in the cytoplasm, whereas a carboxy-terminal fragment (residues 1032-
2115) was correctly targeted to the nucleus. A computer search of the sequence between residues 1032 and 2115 located two possible NLS sites, LAKKEK 
TABLE 1

Localization of Different NuMA Constructs after Transfection (TF) of BHK of HeLa Cells with Wild-Type, Truncated $(\Delta)$, or Point Mutants (FLm)

\begin{tabular}{|c|c|c|c|c|c|}
\hline \multirow[b]{2}{*}{ NuMA protein } & \multirow[b]{2}{*}{ Localization } & \multicolumn{2}{|c|}{$\begin{array}{c}\approx 20 \mathrm{~h} \\
\text { post-TF }\end{array}$} & \multicolumn{2}{|c|}{$\begin{array}{c}\approx 40 \mathrm{~h} \\
\text { post-TF }\end{array}$} \\
\hline & & BHK & HeLa & BHK & HeLa \\
\hline \multirow[t]{3}{*}{ Wild-type } & N & 72 & 93 & 70 & 97 \\
\hline & $\mathrm{N}+\mathrm{C}$ & 28 & 7 & 30 & 3 \\
\hline & C & 0 & 0 & 0 & 0 \\
\hline \multirow[t]{3}{*}{$\Delta 2005$} & $\mathrm{~N}$ & 59 & 81 & 77 & 94 \\
\hline & $\mathrm{N}+\mathrm{C}$ & 30 & 20 & 21 & 6 \\
\hline & C & 11 & 0 & 3 & 0 \\
\hline \multirow[t]{3}{*}{$\Delta 2003$} & $\mathrm{~N}$ & 2 & 0 & 0 & 0 \\
\hline & $\mathrm{N}+\mathrm{C}$ & 0 & 0 & 13 & 2 \\
\hline & C & 98 & 100 & 87 & 98 \\
\hline \multirow[t]{3}{*}{ FL m2004 + 2005} & $\mathrm{~N}$ & 1 & 16 & 25 & 41 \\
\hline & $\mathrm{N}+\mathrm{C}$ & 24 & 18 & 53 & 45 \\
\hline & C & 74 & 67 & 22 & 14 \\
\hline \multirow[t]{3}{*}{ FL m1989 } & $\mathrm{N}$ & 12.5 & 37 & 16 & 37.5 \\
\hline & $\mathrm{N}+\mathrm{C}$ & 42 & 49 & 61 & 62.5 \\
\hline & C & 45 & 14 & 24 & 0 \\
\hline \multirow[t]{3}{*}{ FL m1988 } & $\mathrm{N}$ & 5 & 0 & 1 & 0 \\
\hline & $\mathrm{N}+\mathrm{C}$ & 10 & 0 & 9 & 20 \\
\hline & C & 86 & 100 & 90 & 80 \\
\hline \multirow{3}{*}{ FL m1984 } & $\mathrm{N}$ & 74 & 93 & 75 & 98 \\
\hline & $\mathrm{N}+\mathrm{C}$ & 26 & 6 & 25 & 2 \\
\hline & C & 0 & 0 & 0 & 0 \\
\hline
\end{tabular}

Note. $\mathrm{N}$, nuclear staining alone; $\mathrm{N}+\mathrm{C}$, nuclear plus cytoplasmic staining; $\mathrm{C}$, cytoplasmic staining alone. Numbers are in percentage.

(residues 1094-1099) and AEKRHR (residues 13771382). These cannot be the NuMA NLS sites since Compton and Cleveland (1993) showed in transfection assays that a tailless NuMA construct (residues 11559 in the Yang nomenclature) remained in the cytoplasm. In contrast, a NuMA derivative covering the tail region (residues 1682 to 2115 in the Yang nomenclature) was correctly targeted to the nucleus. Tang et al. reported in [15] that the 36 amino acids from residue 1972 to 2007 , fused to $\beta$-galactosidase, correctly tar-
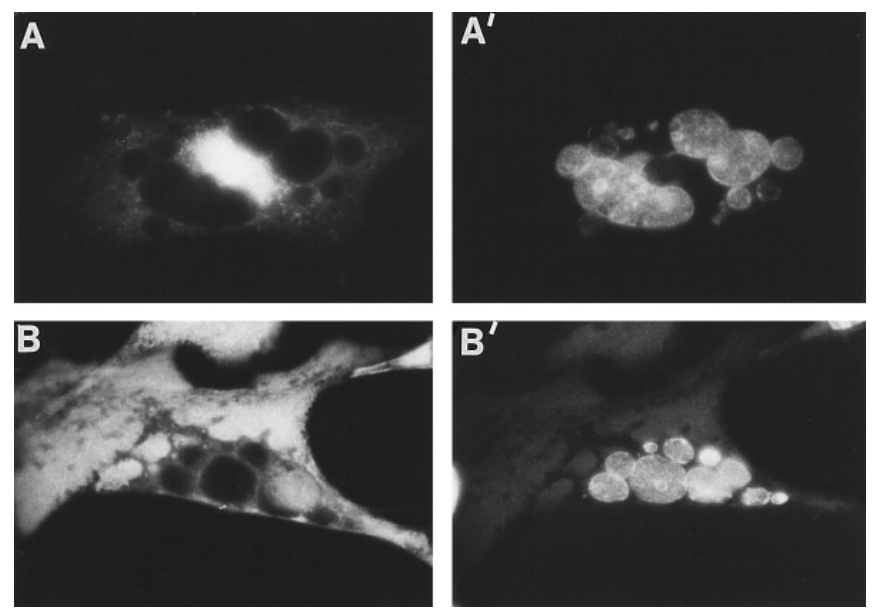

FIG. 9. Induction of micronuclei in BHK cells transfected with truncated NuMA cDNAs. BHK cells transfected with $\triangle 1977\left(A, A^{\prime}\right)$ or $\triangle 1800$ CDNA $\left(B, B^{\prime}\right)$. Cells were stained with the NuMA SPN-3 antibody $(A, B)$ and with Hoechst $\left(A^{\prime}, B^{\prime}\right) .\left(A, A^{\prime}\right) \times 800 ;\left(B, B^{\prime}\right) \times 450$.

geted the enzyme to the nucleus. They also demonstrated the importance of the RKR sequence (residues 1987-1989) since a $K \rightarrow E$ change at position 1988 abolished the nuclear localization. In contrast, and as they stated "to their surprise," when the product of a second construct, QQRKRVS, covering NuMA residues 1985- 1991 was fused to $\beta$-galactosidase the enzyme was mostly located in the cytoplasm.

Our data allow us to resolve this apparent paradox. $\triangle 2005$ and longer constructs target NuMA to the nucleus, while $\Delta 2003$ and shorter constructs result in a cytoplasmic location (Table 1, Fig. 8). In addition, mutation of residues 2004 and 2005 in the full-length molecule results in NuMA accumulating in the cytoplasm. Only at later times is it targeted into the nucleus with a strongly reduced efficiency (Table 1, cf. J enster et al. [22] and Takemoto et al. [23]). Results with mutants in which single amino acids are mutated suggest that a $R \rightarrow G$ change at position 1984 does not affect nuclear localization. In contrast, a $\mathrm{K} \rightarrow$ I change

TABLE 2

Number and Percentage of Cells with Micronuclei 36 and $60 \mathrm{~h}$ after Transfection of BHK Cells with Full-Length NuMA or with Carboxy-Terminally Truncated $(\Delta)$ NuMA Constructs

\begin{tabular}{lccccccc}
\hline Recombinant NuMA & Control & Full length & $\Delta 2005$ & $\Delta 1977$ & $\Delta 1800$ & $\Delta 1700$ & $\Delta 1559$ \\
\hline 36 h posttransfection & & & & & & & \\
$\quad$ No. with micronuclei/total & $1 / 121$ & $2 / 152$ & $7 / 181$ & $35 / 211$ & $33 / 228$ & $36 / 246$ & $22 / 124$ \\
$\quad \begin{array}{l}\text { Percentage } \\
\text { h h posttransfection }\end{array}$ & 1 & 1 & 4 & 17 & 15 & 15 \\
$\quad \begin{array}{l}\text { No. with micronuclei/total } \\
\text { Percentage }\end{array}$ & $5 / 105$ & $6 / 110$ & $21 / 166$ & $80 / 244$ & $52 / 113$ & $58 / 148$ \\
\end{tabular}

Note. Control cells were mock transfected. A cell was scored as micronucleated when Hoechst staining showed more than three nuclei with at least two of them of reduced size. This avoided counting syncitial cells, which are frequent after transfection, as micronucleated. 

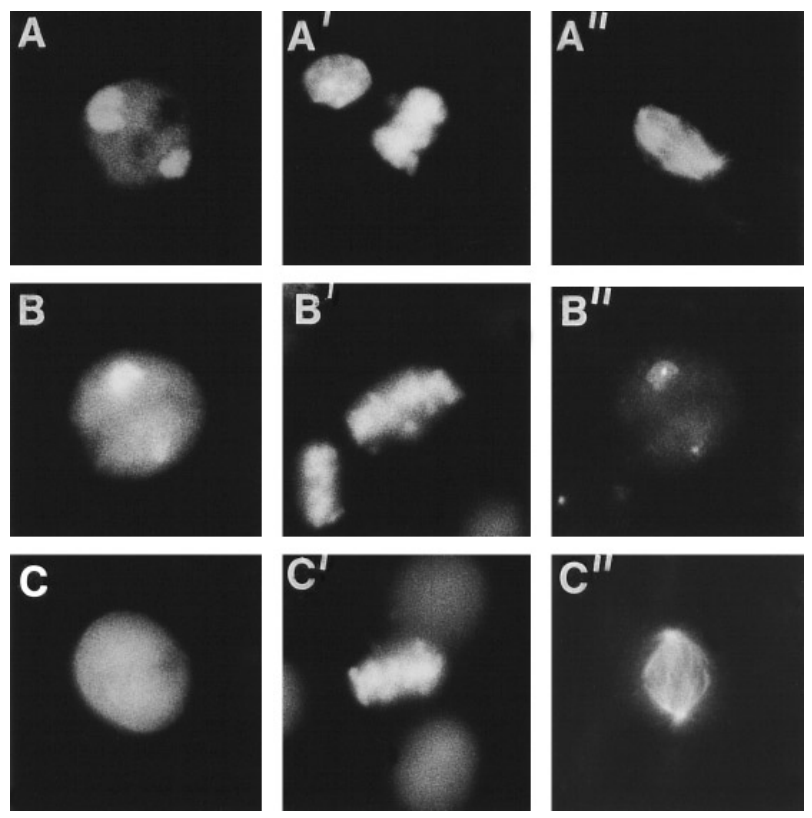

FIG. 10. Immunofluorescence of mitotic BHK cells $48 \mathrm{~h}$ after transfection with truncated NuMA cDNAs. (A-A") $\Delta 1964$, (B-B") $\Delta 1950$, and (C-C") $\Delta 1559$ CDNAs. Cells were triply stained with either NuMA antibody $(A, C)$, Hoechst $\left(A^{\prime}, C^{\prime}\right)$, and tubulin antibody $\left(A^{\prime \prime}, C^{\prime \prime}\right)$ or with NuMA antibody $(B)$, Hoechst $\left(B^{\prime}\right)$, and $\gamma$-tubulin antibody $\left(B^{\prime \prime}\right)$. NuMA staining is increased at the spindle poles in cells in (A) and (B) but not in (C). NuMA staining in (A) looks abnormal (cf. Fig. 3B). $\times 800$.

at position 1988 prevents targeting of NuMA to the nucleus and a $\mathrm{R} \rightarrow \mathrm{G}$ change at position 1989 reduced it appreciably (Table 1). Our data demonstrate that N UMA has a bipartite NLS involving at least the basic residues KR at positions 1988- 1989 and the basic residues KK at positions 2004 and 2005. Figure 8C shows that the NuMA NLS with its two clusters of basic amino acids separated by 14 amino acids displays strong homology with other bipartite localization signals, including those of nucleoplasmin [24], transcription factor ADR1 [25], and the influenza virus polymerase basic protein 1 [26].
Other F unctional Properties of the Tail Domain

Single cytoplasmic NuMA aggregates colocate with the centrosome in BHK cells transfected with the FLNuMA or with the $\Delta 2030, \Delta 2007$, or $\Delta 2005$ constructs (Table 4, column 2). Such aggregates probably form from the excess molecules provided by transfection, which cannot locate to the nucleus because the putative binding sites for NuMA within the nucleus become saturated. Indeed, the percentage of cells in which single cytoplasmic aggregates was seen increased to $90 \%$ in BHK cells transfected with constructs $\Delta 2003-\Delta 1890$ which lack a NLS, again suggesting that NuMA molecules which cannot enter the nucleus locate preferentially to the centrosome region (Table 4). $\Delta 1839$ and shorter mutants instead form multiple aggregates or sheet-like structures, similar to those reported by Compton and Cleveland [10] or by Tang et al. [6] for other tailless NuMA constructs.

Overexpression of certain NuMA constructs resulted in patterns which convey a filamentous or rod-like impression (Table 4, col umn 3). The filament bundles seen in $1-3 \%$ of cells transfected with FLNuMA or with the $\Delta 2030, \Delta 2007$, or $\Delta 2005$ constructs might represent a low but inherent capacity of NuMA to form filaments relevant to the role postulated for NuMA in the interphase nucleus $[1,2,11]$. However, in vitro studies thus far provide no evidence that NuMA can form filaments (for discussion see [14]), and, indeed, NuMA seems to lack the typical periodicities found in the helical arrays of other filament forming proteins [27]. Thus, alternate explanations of the filament bundles such as NuMA becoming bound to, or trapped by, a filamentous cytoskeletal component seem possible. The multiple short rod-like structures surrounding the centrosome seen in around $20 \%$ of cells transfected with the NuMA $\Delta 1977$ or $\Delta 2003$ constructs might represent intermediates which cannot assemble into longer filaments due to the C-terminal truncations (Fig. 4E). Alternatively, they could represent paracrystals (cf. [28]). Finally, in cells transfected with $\Delta 1964$ or shorter mutants, neither filaments nor rods were seen.

Our results suggest that the presence of large NuMA

TABLE 3

Localization of Full-Length and Different Tail-Truncated $(\Delta)$ NuMA Proteins in Mitotic Transfected BHK Cells as Detected by Staining with the SPN-3 Antibody

\begin{tabular}{|c|c|c|c|c|c|c|}
\hline Recombinant NuMA & Full length & $\Delta 1839$ & $\Delta 1800$ & $\Delta 1750$ & $\Delta 1700$ & $\Delta 1559$ \\
\hline $\begin{array}{l}\text { Transfected mitotic cells } \\
\text { NuMA staining pattern }\end{array}$ & 16 & 14 & 32 & 19 & 13 & 7 \\
\hline $\begin{array}{l}\text { Diffuse staining } \\
\text { Spindle pole staining }\end{array}$ & 2 (13\%) & 2 (14\%) & $12(38 \%)$ & $19(100 \%)$ & 13 (100\%) & 7 (100\%) \\
\hline $\begin{array}{l}\text { Dot- or crescent-like } \\
\text { Polar aggregates }\end{array}$ & $\begin{array}{l}8(50 \%) \\
6(38 \%)\end{array}$ & $\begin{array}{l}5(36 \%) \\
7(50 \%)\end{array}$ & $\begin{array}{r}6(19 \%) \\
14(44 \%)\end{array}$ & $\begin{array}{l}0 \\
0\end{array}$ & $\begin{array}{l}0 \\
0\end{array}$ & $\begin{array}{l}0 \\
0\end{array}$ \\
\hline
\end{tabular}


TABLE 4

Summary of Results Obtained with Full-Length NuMA and with Each of the Tail-Truncated NuMA Constructs

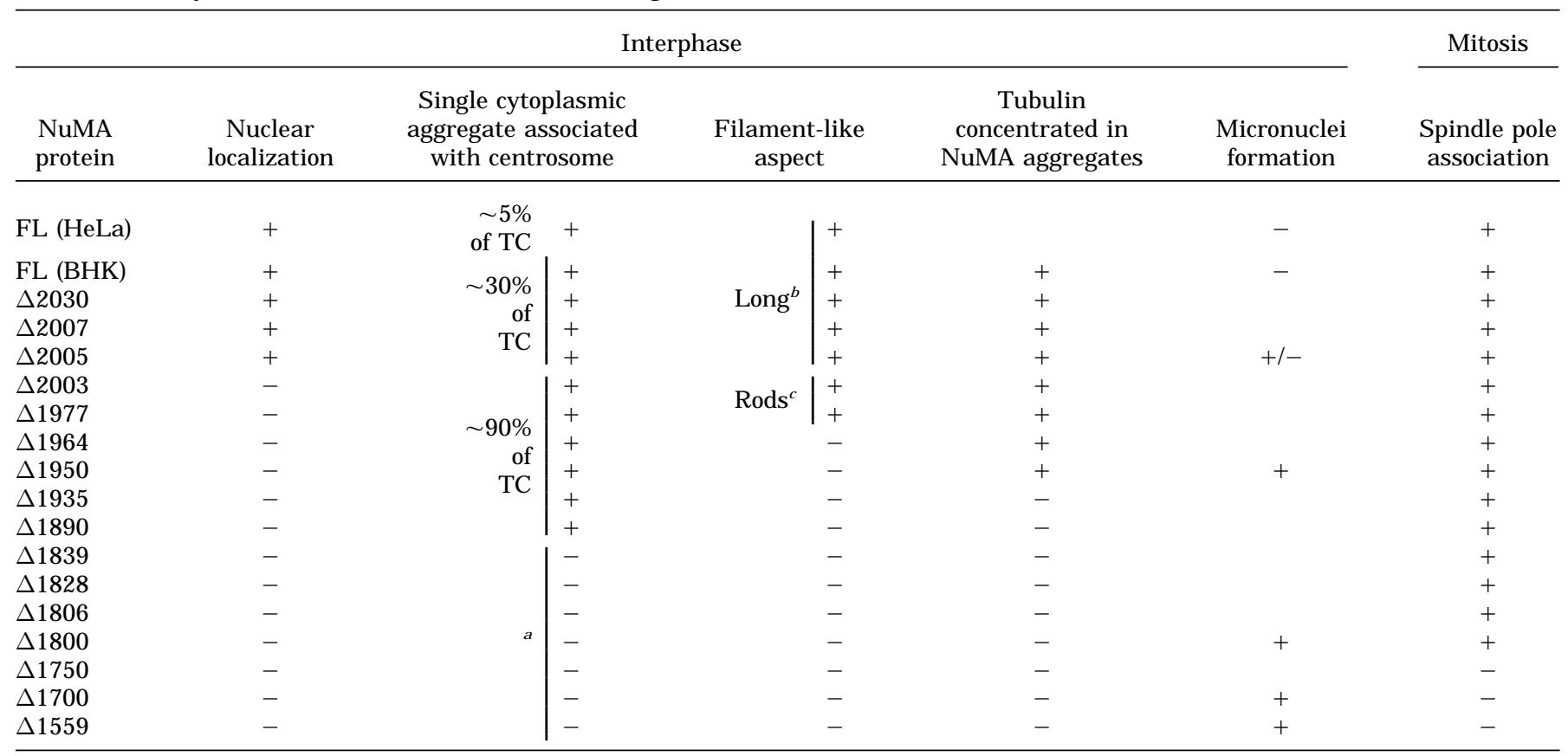

Note. FL, full length; TC, transfected cells.

a More than one aggregate or homogeneous distribution.

${ }^{b}$ Observed in $\sim 1 \%$ of the cells.

c Observed in $\sim 20 \%$ of the cells.

aggregates in the cytoplasm of cells expressing $\Delta 1950$, longer constructs, or FLNuMA resulted in a distortion of the cytoplasmic microtubular network (Table 4, column 4). In such cells the NuMA aggregates were al so strongly stained by the tubulin antibody, while the density of the microtubules in the remainder of the cell was very much reduced when compared to untransfected cells (cf. Figs. $5 A$ and $5 A^{\prime}$ ). These data could indicate a direct interaction of NuMA with tubulin (or even with microtubules) and are consistent with the binding of NuMA to taxolstabilized microtubules [4, 7] mapped to residues 1503 to 2115 [13]. The large amount of NuMA present in such cells might not allow efficient posttranslational modification, and thus the typical interphase modifications, which normally would preclude the interactions of NuMA with the cytoplasmic microtubules of interphase cells, might not occur.

NuMA is important for postmitotic nuclear reformation $[2,8,10]$. Our results on micronuclei formation after transfection of BHK cells with the different N uMA constructs are summarized in Table 2 and Table 4 , column 5 . They suggest that a region important for normal nuclear reformation postmitosis lies in the Cterminal 130 residues of NuMA, i.e., in the part of the NuMA molecule which includes the nuclear location signal. We note also that this region is unusually rich in charged residues $(15 \mathrm{R}, 15 \mathrm{~K}, 3 \mathrm{H}, 4 \mathrm{E}$, and $2 \mathrm{D})$ and very basic, with a calculated isoelectric point of 12.5 .

Finally, NuMA is important in the setting up and/or stabilization of the mitotic spindle $[2,8,9]$ and thus an analysis of the association of NuMA with the spindle poles is of special interest. The tail domain has been shown to be involved in the binding of N UMA to spindle poles [10, 13]. Analysis of our NuMA mutants emphasizes that the sequence between residues 1750 and 1800 is important for spindle association (Tables 3 and 4). This result is consistent with the data cited above, as well as with a recent report that a $\beta$-gal/NuMA 1538- 2115 construct associates with spindle poles in mitotic cells, whereas the chimeric protein $\beta$-gal/NuMA 1538 - 1725 does not [15] (however, note the $\Delta 1667$ construct in ref. [15] which appeared to bind to the spindle poles, albeit with a reduced binding efficiency). In intact NuMA molecules p34 ${ }^{\text {cdc-2 }}$ kinase sites in the tail region also seem to be of critical importance [16], since mutation of threonine 2041 (2055 in the Yang et al. nomenclature) alone or in combination with mutations in other potential p43 cdc-2 phosphorylation sites led to a reduction in binding and these mutant NuMA forms concentrate instead to the plasma membrane. However, all except 1 of the 15 recombinant expression clones we constructed lack the four potential p34 ${ }^{\text {cdc-2 }}$ 
kinase sites, but 13 of these still bind to the spindle poles in transfected mitotic cells (Table 4). The combined results suggest that more than one site may be important for the correct targeting of NuMA to the spindle poles, either because they bind directly to spindle pole components or because their presence is required so that NuMA can adopt the correct structure for binding.

We thank Dr. Mark Stinski, University of Iowa, for the pCMV5 vector, Dr. Michel Wright, CNRS Toulouse, for the $\gamma$-tubulin antibody, and Dr. M. Kirschner for the 5051 antibody. We thank Dr. J ens Harborth for sharing his technical expertise and for discussion, Dr. Volker Gerke for advice on molecular cloning and for comments on the manuscript, and I rene Gajewski for photographic assistance. The work was supported by a postdoctoral fellowship from the EU Human Capital and Mobility Program to C.H. and in part by a grant from the Deutsche Forschungsgemeinschaft to M.O. Data on the NuMA NLS were presented at the ECBO Meeting in Heidelberg in April 1995.

\section{REFERENCES}

1. Lydersen, B. K., and Pettijohn, D. E. (1980) Cell 22, 489-499.

2. Kallajoki, M., Weber, K., and Osborn, M. (1991) EMBO J . 10, 3351- 3362.

3. Tousson, A., Zeng, C., Brinkley, B. R., and Valdivia, M. M. (1991) J . Cell Biol. 112, 427-440.

4. Maekawa, T., Leslie, R., and Kuriyama, R. (1991) Eur. J . Cell Biol. 54, 255- 267.

5. Compton, D. A., Yen, T. J ., and Cleveland, D. W. (1991) J . Cell Biol. 112, 1083- 1097.

6. Tang, T. K., Tang, C. C., Chen, Y.-L., and Wu, C.-W. (1993) J . Cell Sci. 104, 249-260.

7. Kallajoki, M., Weber, K., and Osborn, M. (1992) J . Cell Sci. 102, 91- 102.

8. Kallajoki, M., Harborth, J., Weber, K., and Osborn, M. (1993) J. Cell Sci. 104, 139-150.

Received February 7, 1996

Revised version received March 11, 1996
9. Yang, C. H., and Snyder, M. (1992) Mol. Biol. Cell 3, 12591267.

10. Compton, D. A., and Cleveland, D. W. (1993) J . Cell Biol. 120, 947-957.

11. Zeng, C., He, D., and Brinkley, B. R. (1994) Cell Mot. Cytoskeleton 29, 167- 176.

12. Compton, D. A., Szilak, I., and Cleveland, D. W. (1992) J . Cell Biol. 116, 1395- 1408.

13. Maekawa, T., and Kuriyama, R. (1993) J . Cell Sci. 105, 589600.

14. Harborth, J ., Weber, K., and Osborn, M. (1995) EMBO J . 14, 2447-2460.

15. Tang, T. K., Tang, C. C., Chao, Y.-J ., and Wu, C.-W. (1994) J . Cell Sci. 107, 1389- 1402.

16. Compton, D. A., and Luo, C. (1995) J . Cell Sci. 108, 621-633.

17. Andersson, S., Davis, D. N., Dahlbäck, H., J örnval, H., and Russel, D. N. (1989) J . Biol. Chem. 264, 8222- 8229.

18. Chen, C., and Okayama, H. (1987) Mol. Cell. Biol. 7, 27452752.

19. J ulian, M., Tollon, Y., Lajoie-Mazenc, I., Moisand, A., Mazarguil, H., Puget, A., and Wright, M. (1993) J . Cell Sci. 105, 145156.

20. Calarco-Gillan, P. D., Siebert, M. C., Hubble, R., Mitchison, T., and Kirschner, M. (1983) Cell 35, 621-629.

21. Dingwall, C., and Laskey, R. A. (1991) Trends Biochem. Sci. 16, 478- 481.

22. J enster, G., Trapman, J ., and Brinkmann, A. O. (1993) Biochem. J. 293, 761- 768.

23. Takemoto, Y., Tashiro, S., Handa, H., and I shii, S. (1994) FEBS Lett. 350, 55- 60.

24. Robbins, J., Dilworth, S. M., Laskey, R. A., and Dingwall, C. (1991) Cell 64, 615-623.

25. Hartshorne, T. A., Blumberg, H., and Young, E. T. (1986) Nature 320, 283- 287.

26. Nath, S. T., and Nayak, D. P. (1990) Mol. Cell. Biol. 10, 41394145.

27. Parry, D. A. D. (1994) Biophys. J . 67, 1203- 1206.

28. Bensch, K. G., and Malawista, S. E. (1969) J . Cell. Biol. 40, 95106. 